\title{
Analisis Video Share To Video Views Ratio Tiktok Pada 6 Rekomendasi Minuman Boba Yang Wajib Dicoba
}

\author{
Yosico Angelica \\ yosicoangelicanyan@gmail.com
}

\begin{abstract}
Tiktok is an application where users can share a short videos with other users. Besides Tiktok, this application can also be known as Douyin. The Tiktok application was first introduced and launched in September 2016. This application was created by Zhang Yiming and developed by Beijing ByteDance Technology from China. In Indonesia, there are 30,7 million active users of the Tiktok Application, which makes this application an opportunity for any brand to make this application as social media marketing platform. There are 6 must-try boba brands that use the Tiktok Application as a marketing platform, namely : Chatime Indonesia, Gulu Gulu Indonesia, Xing Fu Tang Indonesia, Kokumi Indonesia, Tiger Sugar Indonesia, The Bobatime Indonesia. The purpose of this study is to calculate the credibility of the Tiktok account performance of the 6 Must-try boba drink brands. The method used for this research is quantitative exploratory method. The results of this study indicate that the Chatime Indonesia Brands is ranked first and has good account performance credibility.
\end{abstract}

\begin{abstract}
ABSTRAK
Tiktok adalah sebuah aplikasi yang dimana para penggunanya dapat berbagi video dengan berdurasi pendek dengan pengguna lainnya. Selain Tiktok, aplikasi ini juga dapat dikenal dengan nama Douyin. Aplikasi Tiktok pertama kali diperkenalkan dan diluncurkan pada September 2016. Aplikasi ini diciptakan oleh Zhang Yiming dan dikembangkan oleh Beijing ByteDance Technology yang berasal dari Tiongkok. Di Indonesia sendiri, terdapat 30,7 juta pengguna aktif aplikasi Tiktok ini yang membuat aplikasi ini dapat memberikan peluang bagi brand apapun untuk menjadikan aplikasi ini sebagai platform social media marketing. Adapun 6 Brand Boba yang wajib dicoba yang memanfaatkan aplikasi Tiktok sebagai platform marketing, yaitu : Chatime Indonesia, Gulu Gulu Indonesia, Xing Fu Tang Indonesia, Kokumi Indonesia, Tiger Sugar Indonesia, The Bobatime Indonesia. Tujuan dari penelitian ini yaitu untuk menghitung kredibilitas dari performa akun Tiktok 6 Rekomendasi Brand Minuman Boba yang wajib dicoba. Metode yang digunakan untuk penelitian ini yaitu metode eksploratif kuantitatif. Hasil dari penelitian ini menunjukkan bahwa Brand Chatime Indonesia mendapatkan peringkat pertama dan memiliki kredibilitas performa akun yang baik.
\end{abstract}




\section{Keyword : Credibility Account Tiktok; Social Media Marketing; Social Media Tiktok, Video Share To Video Views Ratio; Brand Rekomendasi Boba Yang Wajib Dicoba.}

\section{PENDAHULUAN}

Perkembangan teknologi informasi yang semakin pesat membuat kita sebagai manusia dipermudah dalam hal berkomunikasi dengan sesama manusia walau dari jarak yang sangat jauh. Perkembangan teknologi ini dapat disebut sebagai Media Sosial. Media Sosial juga sangat berkembang dengan pesat. Dari yang awalnya hanya satu atau dua jenis, kini media sosial memiliki banyak variasi jenis. Salah satu variasi sosial media tersebut adalah sosial media yang dapat berbagi video pendek ke sesama penggunanya. Sosial media ini disebut Tiktok.

Tiktok adalah sebuah aplikasi yang dimana para penggunanya dapat berbagi video dengan berdurasi pendek dengan pengguna lainnya. Aplikasi Tiktok pertama kali diperkenalkan dan diluncurkan pada September 2016. Aplikasi ini diciptakan oleh Zhang Yiming dan dikembangkan oleh Beijing ByteDance Technology yang berasal dari Tiongkok. Di Indonesia sendiri, terdapat 30,7 juta pengguna aktif sosial media Tiktok. Banyaknya pengguna aktif yang menggunakan sosial ini memberikan peluang bagi para brand untuk memanfaatkan Tiktok sebagai platform untuk membangun brand - nya dan juga sebagai platform media sosial marketing yang menjanjikan.

Banyak brand - brand maupun perusahaan yang terkenal di Indonesia yang menggunakan sosial media Tiktok sebagai platform media sosial marketing mereka. Contohnya 6 Brand Boba Kekinian yang sangat direkomendasikan untuk dicoba yaitu : Chatime Indonesia, Gulu Gulu Indonesia, Xing Fu Tang Indonesia, Kokumi Indonesia, Tiger Sugar Indonesia, dan The Bobatime Indonesia (6 Rekomendasi Minuman Boba yang Wajib Dicoba - Indozone)

Penelitian ini menggunakan metode eksploratif kuantitatif, dan akan menghitung menggunakan rasio - rasio yang ada pada sosial media Tiktok. Pada penelitian (Permana dan Meinarni 2021) menjelaskan bahwa terdapat 17 rasio yang ada pada sosial media Tiktok dan relevan digunakan sebagai media ukur kredibilitas akun yang ada. Penelitian ini hanya berfokus untuk menghitung kredibilitas Video Share to Video Views Ratio pada 6 Rekomendasi Minuman Boba yang Wajib Dicoba. Tujuan dari penelitian ini adalah mengetahui kredibilitas performa dari akun Tiktok 6 Rekomendasi Minuman Boba yang Wajib Dicoba menggunakan Video Share to Video Views Ratio.

\section{TINJAUAN PUSTAKA}

Perkembangan bidang teknologi saat ini terjadi begitu pesat. Melalui perkembangan yang terjadi dari waktu ke waktu menimbulkan maraknya aplikasi - aplikasi serta platform media sosial yang bermunculan. Aplikasi yang sangat diminati oleh masyarakat saat ini diantaranya adalah TikTok, Instagram, Twitter, WhatsApp dan yang lain sebagainya. Seiring berjalannya waktu, aplikasi sosial media tersebut dapat menjadi candu bagi kalangan masyarakat. Tidak hanya kalangan remaja yang menggunakan aplikasi sosial media, orang tua bahkan anak-anak 
juga aktif menggunakan aplikasi sosial media tersebut. Tiktok merupakan bagian dari new media yang memiliki perkembangan terpesat dibandingkan dengan kategori new media yang lainnya seperti facebook, Instagram, YouTube, dan Twitter (P3M STMIK Widya Cipta Dharma n.d.) .

Dari sekian banyak aplikasi sosial media, TikTok menjadi aplikasi yang memiliki pengguna aktif terbanyak. TikTok merupakan jejaring sosial media dalam bentuk video yang umumnya berdurasi 15 detik. Pada aplikasi TikTok pengguna dapat membuat video dengan filter-filter yang spesial serta menggunakan lagu yang sedang trending. Selain itu, pengguna dapat membagikan video yang dibuat ke aplikasi lain seperti Instagram atauoun Twitter (PRIANBODO 2018) .

Salah satu ciri khas sosial media TikTok adalah halaman utamanya yang Bernama For Your Page atau FYP. Pengguna yang cukup sering ditayangkan dalam FYP dapat menjadi popular dan memiliki banyak pengikut, yang biasa disebut sebagai seleb TikTok (Putri and Azeharie 2021).

Di Indonesia, fenomena anak muda dalam menggunakan TikTok menunjukan antusiasme yang sangat massif. Meraka berlomba membangun identitas demi mendapatkan citra yang diinginkan, seperti dipuji dan dikenal oleh banyak orang (Wijaya and Mashud 2020). Aplikasi TikTok semakin populer sejak diluncurkan tahun 2016. Bahkan TikTok telah mencetak berbagai macam prestasi, salah satunya yaitu menyalip pendapatan iklan digital di negatanya yaitu pendapat Google China, Patio (Batam 2020) .

Aplikasi TikTok tidak hanya digunakan untuk membuat konten video dengan tujuan menghibur pengguna lainnya. Aplikasi TikTok juga dapat dijadikan peluang bagi brand atau perusahaan sebagai platform social media marketing. Penelitian (Purnamasari and Tutiasri 2021) menyatakan bahwa TikTok berpengaruh positif dan signifikan terhadap minat beli atau berbelanja secara online. Sehingga dengan ini, TikTok mampu memberikan peluang yang sangat tinggi bagi perusahaan-perusahaan dalam melakukan digital marketing.

TikTok dirasakan memiliki kekuatan ataupun pengaruh dalam industri, sehingga menimbulkan kualitas akun yang menentukan strata maupun kredibilitas pemilik akun. Kredibilitas akun TikTok merupakan suatu hal yang cukup penting untuk berbagai kepentingan. Kredibilitas sebuah akun TikTok dapat diukur dari tingkat performa yang dihasilkan secara matematis. Dalam mengukur performa diperlukan skala pengukuran yang tertuang ke dalam rasio.

\section{METODE PENELITIAN}

Penelitian ini menggunakan metode eksploratif kuantitatif untuk mengetahui kredibilitas dari performa 6 akun Tiktok Rekomendasi Minuman Boba yang Wajib Dicoba. Metode eksploratif adalah penelitian terhadap permasalahan yang belum pernah dijejaki, belum pernah diteliti orang lain sehingga walaupun dalam "kegelapan" peneliti eksplorasi tetap berusaha menemukan permasalahan yang sedang atau akan di teliti tersebut. Bungin (2013:28)

Tujuan dari penelitian ini yaitu mengetahui nilai kredibilitas dari performa akun TikTok 6 Rekomendasi Minuman Boba yang wajib Dicoba. Ada beberapa langkah yang harus dilakukan dalam penelitian ini, sehingga mampu menemukan peringkat pertama akun TikTok 6 
Rekomendasi Minuman Boba yang wajib Dicoba yang memiliki performa terbaik. Langkah langkah yang dilakukan pada penelitian ini, diantaranya yaitu :

\section{Melakukan Eksplorasi Pada Website Untuk Menentukan Objek yang Akan Dianalisa}

Eksplorasi ini dilakukan pada halaman - halaman website yang memiliki dan menyediakan informasi mengenai objek yang di teliti. Setelah eksplorasi selesai dilakukan, ditemukan nama - nama brand 6 rekomendasi minuman boba yang wajib dicoba yang akan dijadikan sebagai objek analisa. Setelah melakukan eksplorasi pada halaman website, maka langkah selanjutnya yaitu mencari nama akun - akun Tiktok dari masing - masing brand boba. Dan Memastikan semua brand memiliki akun pada aplikasi sosial media Tiktok.

2. Menghitung Nilai Rata - Rata Variabel Dari 6 Rekomendasi Minuman Boba yang Wajib Dicoba

Pada langkah ini, peneliti menghitung nilai variable video share dan variable video views. Variabel merupakan sesuatu yang memiliki nilai yang bervariasi dimana nilai tersebut dapat dijadikan sebagai dasar untuk empat data yang berbeda seperti rasio, skala, ordinal, nominal dan internal (Rankuti 2015). Untuk menghitung nilai rata - rata dari variable video share dan video views yaitu dengan cara mengambil minimal 10 postingan yang ada di masing masing akun Tiktok Brand tersebut kemudian dihitung sehingga menemukan nilai rata - rata dari masing - masing variable.

\section{Menghitung Nilai Kredibilitas Rasio}

Untuk menghitung nilai kredibilitas dari video share to video views ratio, peneliti menggunakan cara membagi nilai variable pertama dengan variable kedua. Jika video share memiliki nilai 100 dan video views memiliki nilai 300, maka cara menghitungnya yaitu $100: 300=0,3$. Dengan begitu nilai dari video share to video views ratio adalah 0,3 .

\section{Menentukan Peringkat Pada Akun Tiktok}

Pada langkah terakhir yang dilakukan pada penelitian ini yaitu untuk menentukan peringkat pada masing masing rasio yang ada. Pada penentuan perangkat ini, perlu melihat karakteristik dari rasio yang diteliti. Jika karakteristik rasio merupakan rendah, maka objek yang memiliki nilai terendah akan mendapatkan angka 6 dan Objek yang memiliki nilai tertinggi akan mendapatkan angka 1. Namun jika rasio memiliki karakteristik tinggi maka objek yang mendapatkan nilai tinggi akan mendapatkan angka 6 dan objek yang mendapatkan nilai terendah akan mendapatkan angka 1. Setelah mendapatkan hasil kredibilitas ratio maka dapat disimpulkan objek yang mana mendapatkan peringkat 1 sampai dengan peringkat 6 . 


\section{HASIL DAN PEMBAHASAN}

Akun Tiktok dari 6 Rekomendasi Minuman Boba Yang Wajib Dicoba, diantaranya :

1. Chatime Indonesia

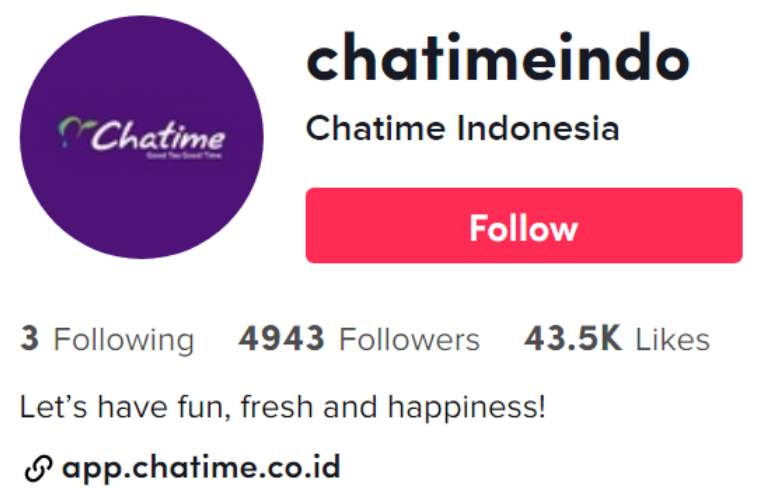

Gambar 1. Akun Tiktok Chatime Indonesia

Sumber : https://www.tiktok.com/@ chatimeindo (diakses pada 19 Oktober 2021)

\section{Gulu Gulu Indonesia}

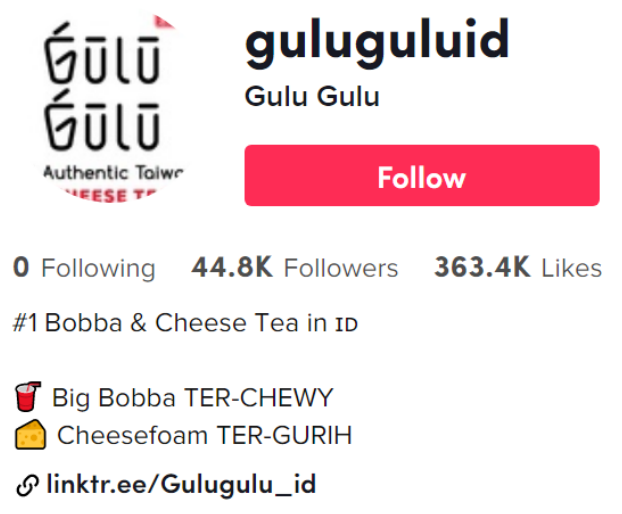

Gambar 2. Akun Tiktok Gulu Gulu Indonesia

Sumber : https://www.tiktok.com/@guluguluid (diakses pada 19 Oktober 2021)

\section{Xing Fu Tang Indonesia}

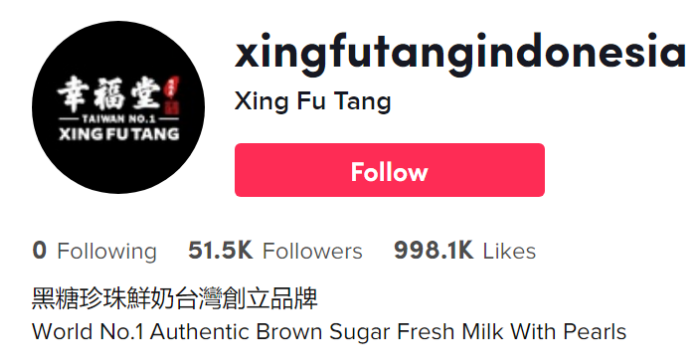

Gambar 3. Akun Tiktok Xing Fu Tang Indonesia

Sumber : https://www.tiktok.com/@xingfutangindonesia (diakses pada 19 Oktober 2021)

\section{Kokumi Indonesia}




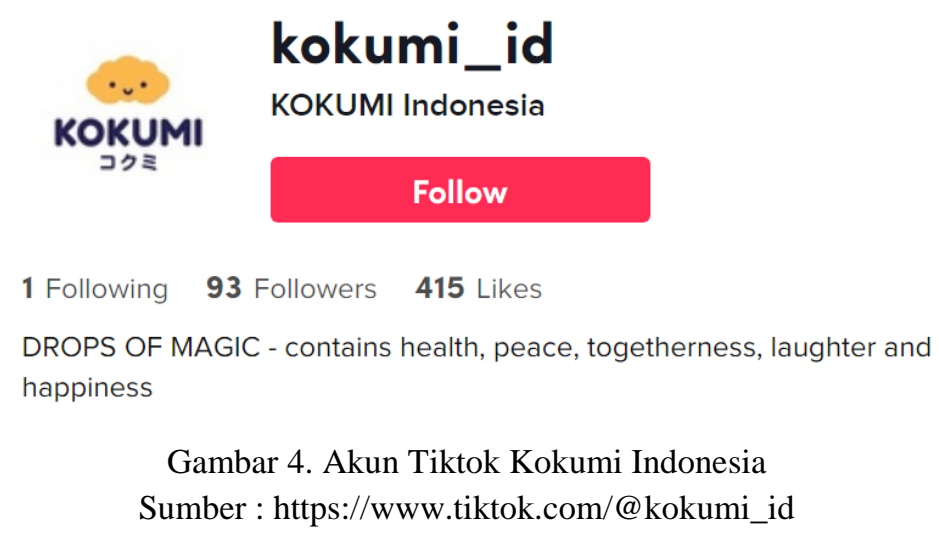

5. Tiger Sugar Indonesia

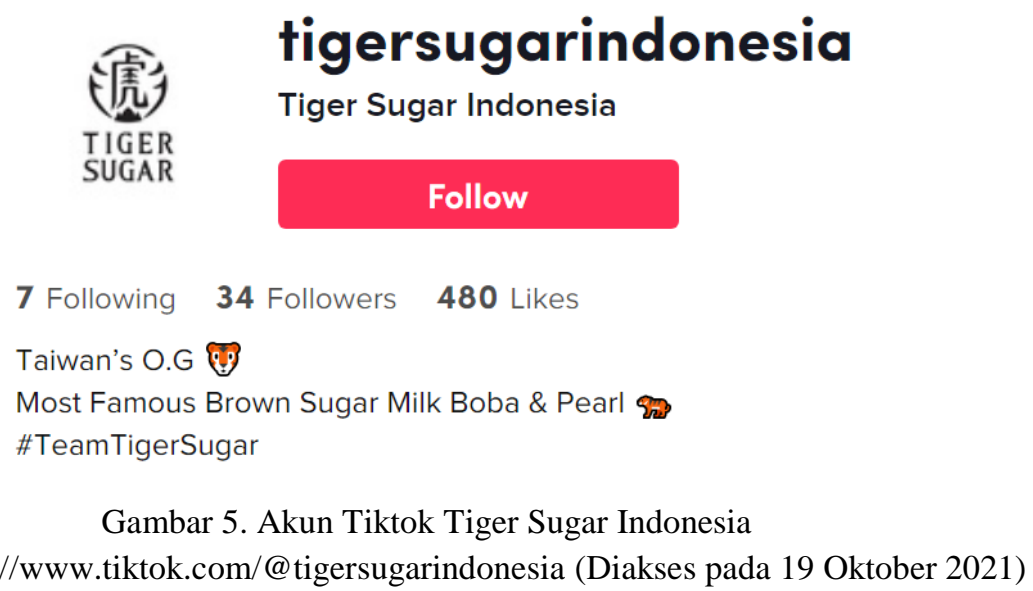

6. The Bobatime Indonesia

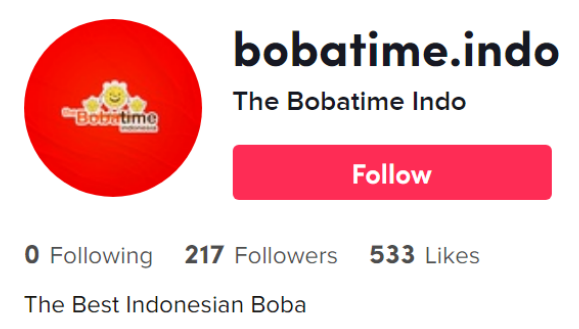

Gambar 6. Akun Tiktok Bobatime Indonesia

Sumber : https://www.tiktok.com/@bobatime.indo (Diakses pada 19 Oktober 2021)

Dari kelima akun Tiktok tersebut, peneliti menemukan nilai dari masing - masing variable yang ada untuk menghitung rasio Video Share to Video Views dari setiap akun. Pada akun Tiktok terdapat 7 Variabel, diantaranya yaitu :

1. Likes

2. Followers

3. Following

4. Video Likes

5. Video Comments

6. Video Share

7. Video Views 
Dari ketujuh variabel tersebut peneliti hanya fokus untuk menemukan hasil dari 2 variabel, yaitu :

1. Video Share

2. Video Views

Dari kedua variable tersebut kemudian dianalisa sehingga menemukan nilai rata - rata dari variable video share dan video views. Untuk menghitung nilai rata - rata dari variable video share dan video views yaitu dengan cara mengambil minimal 10 postingan kemudian di hitung sehingga menemukan nilai rata - rata dari masing - masing variable. Berikut merupakan nilai rata - rata dari masing - masing merek boba kekinian, yaitu :

Tabel 1. Analisa Nilai Rata - Rata Nilai Variabel Video Share dan Video Views Akun Tiktok Chatime Indonesia

\begin{tabular}{|c|c|c|}
\hline No & $\begin{array}{c}\text { Video } \\
\text { Share }\end{array}$ & $\begin{array}{c}\text { Video } \\
\text { Views }\end{array}$ \\
\hline 1 & 0 & 148 \\
\hline 2 & 5 & 538 \\
\hline 3 & 3 & 1007 \\
\hline 4 & 19 & 17000 \\
\hline 5 & 0 & 943 \\
\hline 6 & 0 & 1371 \\
\hline 7 & 6 & 1136 \\
\hline 8 & 0 & 853 \\
\hline 9 & 0 & 838 \\
\hline 10 & 0 & 932 \\
\hline Rata - Rata & $\mathbf{3 , 3}$ & $\mathbf{2 4 7 6 , 6}$ \\
\hline
\end{tabular}

Sumber : Pengolah Data Excel

Tabel 2. Analisa Nilai Rata - Rata Nilai Variabel Video Share dan Video Views Akun Tiktok Gulu Gulu Indonesia

\begin{tabular}{|c|c|c|}
\hline No & $\begin{array}{c}\text { Video } \\
\text { Share }\end{array}$ & $\begin{array}{c}\text { Video } \\
\text { Views }\end{array}$ \\
\hline 1 & 23 & 400100 \\
\hline 2 & 2 & 93600 \\
\hline 3 & 216 & 1.900 .000 \\
\hline 4 & 0 & 1218 \\
\hline 5 & 0 & 202 \\
\hline 6 & 4 & 504 \\
\hline 7 & 0 & 236 \\
\hline 8 & 0 & 15600 \\
\hline
\end{tabular}




\begin{tabular}{|c|c|c|}
9 & 1 & 296 \\
\hline 10 & 0 & 206 \\
\hline Rata - Rata & $\mathbf{2 4 , 6}$ & $\mathbf{2 4 1 1 9 6 , 2}$ \\
\hline
\end{tabular}

Sumber : Pengolahan Data Excel

Tabel 3. Analisa Nilai Rata - Rata Nilai Variabel Video Share dan Video Views Akun Tiktok Xing Fu Tang Indonesia

\begin{tabular}{|c|c|c|}
\hline No & $\begin{array}{c}\text { Video } \\
\text { Share }\end{array}$ & $\begin{array}{c}\text { Video } \\
\text { Views }\end{array}$ \\
\hline 1 & 0 & 526 \\
\hline 2 & 0 & 745 \\
\hline 3 & 0 & 518 \\
\hline 4 & 1 & 704 \\
\hline 5 & 0 & 1265 \\
\hline 6 & 0 & 18.200 \\
\hline 7 & 0 & 669 \\
\hline 8 & 0 & 2425 \\
\hline 9 & 0 & 1410 \\
\hline 10 & 1 & 33.200 \\
\hline Rata - Rata & $\mathbf{0 , 2}$ & $\mathbf{5 9 6 6 , 2}$ \\
\hline
\end{tabular}

Sumber : Pengolah Data Excel

Tabel 4. Analisa Nilai Rata - Rata Nilai Variabel Video Share dan Video Views Akun Tiktok Kokumi Indonesia

\begin{tabular}{|c|c|c|}
\hline No & $\begin{array}{c}\text { Video } \\
\text { Share }\end{array}$ & $\begin{array}{c}\text { Video } \\
\text { Views }\end{array}$ \\
\hline 1 & 15 & 155 \\
\hline 2 & 3 & 181 \\
\hline 3 & 3 & 586 \\
\hline 4 & 8 & 511 \\
\hline 5 & 2 & 72 \\
\hline 6 & 0 & 88 \\
\hline 7 & 2 & 164 \\
\hline 8 & 2 & 129 \\
\hline 9 & 5 & 640 \\
\hline 10 & 5 & 215 \\
\hline Rata - Rata & $\mathbf{4 , 5}$ & $\mathbf{2 7 4 , 1}$ \\
\hline
\end{tabular}

Sumber : Pengolahan Data Excel 
Tabel 5. Analisa Nilai Rata - Rata Nilai Variabel Video Share dan Video Views Akun Tiktok Tiger Sugar Indonesia

\begin{tabular}{|c|c|c|}
\hline No & $\begin{array}{c}\text { Video } \\
\text { Share }\end{array}$ & $\begin{array}{c}\text { Video } \\
\text { Views }\end{array}$ \\
\hline 1 & 0 & 40 \\
\hline 2 & 0 & 60 \\
\hline 3 & 0 & 53 \\
\hline 4 & 0 & 43 \\
\hline 5 & 0 & 50 \\
\hline 6 & 0 & 31 \\
\hline 7 & 0 & 43 \\
\hline 8 & 0 & 54 \\
\hline 9 & 0 & 61 \\
\hline 10 & 0 & 67 \\
\hline $\begin{array}{c}\text { Rata }- \\
\text { Rata }\end{array}$ & $\mathbf{0}$ & $\mathbf{5 0 , 2}$ \\
\hline
\end{tabular}

Sumber : Pengolahan Data Excel

Tabel 6. Analisa Nilai Rata - Rata Nilai Variabel Video Share dan Video Views Akun Tiktok The Bobatime Indonesia

\begin{tabular}{|c|c|c|}
\hline No & $\begin{array}{c}\text { Video } \\
\text { Share }\end{array}$ & $\begin{array}{c}\text { Video } \\
\text { Views }\end{array}$ \\
\hline 1 & 4 & 949 \\
\hline 2 & 8 & 899 \\
\hline 3 & 2 & 995 \\
\hline 4 & 0 & 798 \\
\hline 5 & 3 & 2200 \\
\hline 6 & 2 & 3.322 \\
\hline 7 & 8 & 2529 \\
\hline 8 & 7 & 1161 \\
\hline 9 & 0 & 689 \\
\hline 10 & 0 & $\mathbf{5 6 5}$ \\
\hline $\begin{array}{c}\text { Rata }- \\
\text { Rata }\end{array}$ & $\mathbf{3 , 4}$ & $\mathbf{1 4 1 0 , 7}$ \\
\hline
\end{tabular}

Sumber : Pengolahan Data Excel

Setelah menghitung nilai rata - rata tersebut, maka akan menemukan hasil akhir nilai rata rata dari variable Video Share dan Video Views 
Tabel 7. Nilai Variabel Pada Akun Tiktok 6 Rekomendasi Minuman Boba Yang Wajib Dicoba

\begin{tabular}{|c|c|c|c|c|c|c|}
\hline Variable & $\begin{array}{c}\text { Chatime } \\
\text { Indonesia }\end{array}$ & $\begin{array}{c}\text { Gulu Gulu } \\
\text { Indonesia }\end{array}$ & $\begin{array}{c}\text { Xing Fu } \\
\text { Tang } \\
\text { Indonesia }\end{array}$ & $\begin{array}{c}\text { Kokumi } \\
\text { Indonesia }\end{array}$ & $\begin{array}{c}\text { Tiger } \\
\text { Sugar } \\
\text { Indonesia }\end{array}$ & $\begin{array}{c}\text { Bobatime } \\
\text { Indonesia }\end{array}$ \\
\hline $\begin{array}{c}\text { Video } \\
\text { Share }\end{array}$ & 3,3 & 24,6 & 0,2 & 4,5 & 0 & 3,4 \\
\hline $\begin{array}{c}\text { Video } \\
\text { Views }\end{array}$ & 2476,6 & 241196,2 & 5966,2 & 274,1 & 50,2 & 1410,7 \\
\hline
\end{tabular}

Sumber : Pengolah Data Excel

Pada akun Tiktok terdapat 17 rasio yang relevan digunakan untuk mengukur kredibilitas pada masing - masing akun. Namun pada penelitian ini hanya berfokus untuk menghitung Video Share to Video Views Ratio. Untuk menghitung kredibilitas dari masing - masing akun Tiktok setiap merek boba kekinian, peneliti menghitung dengan cara : variable 1 akan dibagi dengan variable 2, sehingga ditemukan hasil analisa dari rasio tersebut.

Tabel 8. Hasil Perhitungan Rasio Akun Tiktok

\begin{tabular}{|c|c|c|c|c|c|c|}
\hline Ratio & $\begin{array}{c}\text { Chatime } \\
\text { Indonesia }\end{array}$ & $\begin{array}{c}\text { Gulu Gulu } \\
\text { Indonesia }\end{array}$ & $\begin{array}{c}\text { Xing Fu } \\
\text { Tang } \\
\text { Indonesia }\end{array}$ & $\begin{array}{c}\text { Kokumi } \\
\text { Indonesia }\end{array}$ & $\begin{array}{c}\text { Tiger } \\
\text { Sugar } \\
\text { Indonesia }\end{array}$ & $\begin{array}{c}\text { Bobatime } \\
\text { Indonesia }\end{array}$ \\
\hline $\begin{array}{c}\text { Video } \\
\text { Share } \\
\text { to } \\
\text { video } \\
\text { Views } \\
\text { Ratio }\end{array}$ & 0,001332472 & 0,000101992 & $3,352 \mathrm{E}-05$ & 0,016417366 & 0 & 0,002410151 \\
\hline
\end{tabular}

Sumber : Pengolahan Data Excel

\begin{tabular}{|l|c|c|c|c|c|c|}
\hline \multirow{2}{*}{ Ratio } & \multicolumn{5}{|c|}{ Nilai } \\
\cline { 2 - 7 } & $\begin{array}{c}\text { Chatime } \\
\text { Indonesia }\end{array}$ & $\begin{array}{c}\text { Gulu Gulu } \\
\text { Indonesia }\end{array}$ & $\begin{array}{c}\text { Xing Fu } \\
\text { Tang } \\
\text { Indonesia }\end{array}$ & $\begin{array}{c}\text { Kokumi } \\
\text { Indonesia }\end{array}$ & $\begin{array}{c}\text { Tiger } \\
\text { Sugar }\end{array}$ & $\begin{array}{c}\text { Bobatime } \\
\text { Indonesia }\end{array}$ \\
\hline $\begin{array}{l}\text { Video Share } \\
\text { to Video } \\
\text { Views Ratio }\end{array}$ & 6 & 2 & 4 & 3 & 1 & 5 \\
\hline
\end{tabular}

Tabel 9. Nilai Rasio Akun Tiktok 6 Rekomendasi Minuman Boba Yang Wajib Dicoba 
Dari tabel Nilai Rasio Akun Tiktok 6 Rekomendasi Minuman Boba Yang Wajib Dicoba dapat disimpulkan bahwa Chatime Indonesia mendapatkan nilai tertinggi untuk rasio Video Share to Video Views. Sedangkan akun Tiktok Tiger Sugar Indonesia mendapatkan nilai terendah untuk rasio ini. Jadi, pada penelitian ini Chatime Indonesia memiliki kredibilitas performa yang lebih baik dibandingkan dengan merk boba kekinian yang lainnya. 


\section{KESIMPULAN}

Tujuan dari penelitian ini adalah mengetahui kredibilitas performa dari akun Tiktok 6 Rekomendasi Minuman Boba yang Wajib Dicoba menggunakan Video Share to Video Views Ratio. 6 Rekomendasi minuman boba tersebut diantaranya : Chatime Indonesia, Gulu Gulu Indonesia, Xing Fu Tang Indonesia, Kokumi Indonesia, Tiger Sugar Indonesia, dan Bobatime Indonesia. Dari keenam minuman boba tersebut dapat disimpulkan bahwa :

1. Peringkat Pertama diraih oleh Chatime Indonesia dengan nilai tertinggi yaitu 0,001332472

2. Peringkat Kedua diraih oleh Bobatime Indonesia dengan nilai 0,002410151

3. Peringkat Ketiga diraih oleh Xing Fu Tang Indonesia dengan nilai 3,352E-05

4. Peringkat Keempat diraih oleh Kokumi Indonesia dengan nilai 0,016417366

5. Peringkat Kelima diraih oleh Gulu Gulu Indonesia dengan nilai 0,000101992

6. Peringkat Keenam diraih oleh Tiger Sugar Indonesia dengan nilai terendah yaitu 0 


\section{DAFTAR PUSTAKA}

“ 6 Rekomendasi Minuman Boba Hits Kekinian yang Wajib Kamu Coba - Indozone.id” n.d. Accessed 8 October 2021. https://www.indozone.id/food/3esa84r/6-rekomendasi-minumanboba-hits-kekinian-yang-wajib-kamu-coba/read-all

Permana, I Putu Hendika, and Ni Putu Suci Meinarni. 2021. "Ratio Analysis on Tiktok (Social Media) for Qualitative Research Using Explorative Methods." Jurnal Ekonomi \&amp; Bisnis JAGADITHA 8 (1): 30-38. https://doi.org/10.22225/JJ.8.1.2944.30-38.

Puspita, Mari. 2020. “TikTok Adalah (Pengertian), Asal, Manfaat, Efek Negatifnya”. Diakses pada 9 November 2021.

P3M STMIK Widya Cipta Dharma. n.d. "SEBATIK VOL 25 NO 1 - Google Books.” 2021. $\begin{array}{llll}\text { Accessed } & \text { October } & 15, & 2021 .\end{array}$ https://www.google.co.id/books/edition/SEBATIK_VOL_25_NO_1/UzsyEAAAQBAJ?hl=id \&amp;gbpv=1\&amp;dq=tiktok+adalah\&amp;pg=PA9\&amp;printsec=frontcover.

PRIANBODO, BAGUS. 2018. "PENGARUH 'TIKTOK' TERHADAP KREATIVITAS REMAJA SURABAYA,” December.

Putri, Shani Dwi, and Suzy Azeharie. 2021. "Strategi Pengelolaan Komunikasi Dalam Membentuk Personal Branding Di Media Sosial Tiktok." Koneksi 5 (2): 280-88. https://doi.org/10.24912/KN.V5I2.10300.

Wijaya, Mukhammad Handy dwi, and Musta' in Mashud. 2020. "Konsumsi Media Sosial Bagi Kalangan Pelajar: Studi Pada Hyperrealitas Tik Tok." Al-Mada: Jurnal Agama, Sosial, Dan Budaya 3 (2): 170-91. https://doi.org/10.31538/ALMADA.V3I2.734.

Purnamasari, Nurjihan Pricillia, and Ririn Puspita Tutiasri. 2021. "Analisis Resepsi Remaja Perempuan Terhadap Gaya Hidup Berbelanja Fashion Melalui Tayangan Video 'Belanja Gak Aturan' Dalam Akun Tiktok @handmadeshoesby.” Jurnal Representamen 7 (01). https://doi.org/10.30996/REPRESENTAMEN.V7I01.5129. 